\title{
Barriers Limiting Clinician Recognition of Intimate Partner Violence
}

\author{
Raghu Venugopal, BSc, MPH/MD '0I \\ Harvard School of Public Health, Harvard University, USA and \\ Faculty of Medicine, Dalhousie University, Halifax, Nova Scotia
}

$\mathrm{O}$

ne in three ever-married women in Nova Scotia faces assault from an intimate partner in her

lifetime, making woman abuse a major public health concern. The role of physicians and medi

cal students in the health care system allows them to address this epidemic, yet a number of barriers diminish their ability to deal with domestic violence, also referred to as intimate partner violence (IPV). Using case-reports, personal correspondence, consensus statements, conference proceedings and clinician publications, this article uniquely presents a systematic review of most known barriers which clinicians face in dealing with intimate partner violence. This study examines personal factors, dissonance between clinician views of private versus public spheres, and structural constraints (such as remuneration and work schedules) as reasons mitigating limited clinician attention to intimate partner violence. Barriers related to medical education and traditional medical curricula, as well as problems facing reform of medical education are presented. Lastly, clinician misconceptions and misinformation and professional circumstances are examined as barriers to IPV recognition. This study shows that there are still numerous personal, educational and structural barriers limiting clinician ability, motivation and support to deal with one of the most prevalent health and social problems facing women. This paper concludes that greater attention needs to be focused within medical education, resident education, and continuing medical education on issues surrounding IPV. Whereas this study identifies numerous barriers facing the recognition of IPV, it remains an important corollary to identify the means to address the removal of such barriers. Increasing knowledge of these barriers is the first step in heightening awareness of this public health and medical problem.

"[A]s medical students and future physicians, we are by no means powerless against this epidemic. Teach us well, give us the knowledge and skills we value, want, and need, and watch us make a difference" (1).

\section{INTRODUCTION}

More than ever before, the call for Canadian physicians and medical students to recognize the importance of addressing family violence is apparent. Within family violence, we must pay particular attention to intimate partner violence (IPV), particularly violence against women by men (2-3), as this public health concern has been traditionally ignored and tacitly accepted. ${ }^{.}$It is time for practitioners to recognize facts including: $30 \%$

Address correspondence to:

Raghu Venugopal

11 Baxter Court, Fredericton, New Brunswick, E3B 6L9 of women's injuries presenting in emergency departments are attributable to IPV; one in nine women at emergency departments present as a result of IPV (regardless of chief complaint); and one in six women suffer physical violence and other abuses, particularly during vulnerable times such as pregnancy (4-6). Clinicians must also recognize their own personal and professional shortcomings in dealing with this grave problem, as this recognition is a vital step towards eradicating IPV.

Though recognition now exists of the role which feminist and battered-women's movements played in bringing this issue to

\footnotetext{
${ }^{\prime}$ Men are also victims of IPV, including men of all sexual orientations. However, since $95 \%$ of adult victims are women, this paper will reflect the gender-laden nature of IPV. Further, since $93 \%$ of rape and/or physical assault, since age 18, is perpetrated by males, this paper will reflect this reality.
} 
national attention during the 1970 's, this was not always the case within medicine (7-8). The consciousness-raising of IPV (led by activists) is distinct from the opposition to child abuse, which is felt to have been led mostly by health professionals, and this dichotomy is not without political implications. These implications include the medical profession's slow confrontation of IPV and initial tepid support of community activists. In recent years, however, recognition and subsequent 'medicalization' of IPV is viewed to have partly depoliticized it. Medicine has thus changed IPV from a moral concern and crime into a clinical problem. Like other social concerns, such as alcoholism, drug addiction or elder abuse, medicine has re-framed IPV into an individualized, identifiable and treatable pathology (9). Despite what some protest as medicine's greater IPV jurisdiction, medicalization has brought some distinct advantages. It has given legitimacy to activist discourse, aided research inquiry, operationalized intervention strategies and added program funding where before it was lacking. This situation should be recognized by clinicians as both a boon and source of frustration for some activists and community leaders (10).

Despite growing public awareness of IPV, its epidemiological quantification, and increasing modes of legal redress, many health professionals lack full commitment to deal with IPV. Thus, in this forum, I will first identify barriers to recognizing IPV. In addition, I will consider the future training of Canadian medical students and the role of continuing medical education. Though a notable collection of case-studies, letters, and personal reflections broach this topic, few systematically list the full range of concerns which clinicians and students face. Further, presenting barriers in this forum is based on the premise that an awareness of potential barriers can help clinicians self-assess themselves if barriers arise and circumvent their occurrence at an early stage of training.

\section{METHODOLOGY AND APPROACH}

A MEDLINE ${ }^{\circledR}$ search was conducted for articles addressing intimate partner violence and domestic violence. The search strategy sought Medical Subject Heading (MeSH) for domestic violence, intimate partner violence, family violence, spousal abuse, and medical education. Specification was made for recent English publications based at North American health care institutions. Government publications were sought for prevalence statistics and interpretation of data was conducted by the author and in conjunction with formal instruction on domestic violence at the Harvard Injury Prevention Unit, Brookline, MA.

\section{IPV PREVALENCE IN
NOVA SCOTIA AND CANADA}

The prevalence, or current number of people suffering from IPV in a given year, is staggering. One in three ever-married Nova Scotian women are assaulted, and of these women, $40 \%$ report their abuse began during pregnancy (11). Abuse is not confined to only physical, verbal or psychologi- cal abuse. For example, among women in same sex relationships, $50 \%$ suffer sexual abuse in addition to other forms of abuse. The complex interplay of many forms of abuse is illustrated through the 'power and control wheel' (Figure 1), demonstrating that the focus of IPV is largely a need by men to exercise power and control as well as traditional forms of male privilege over women.

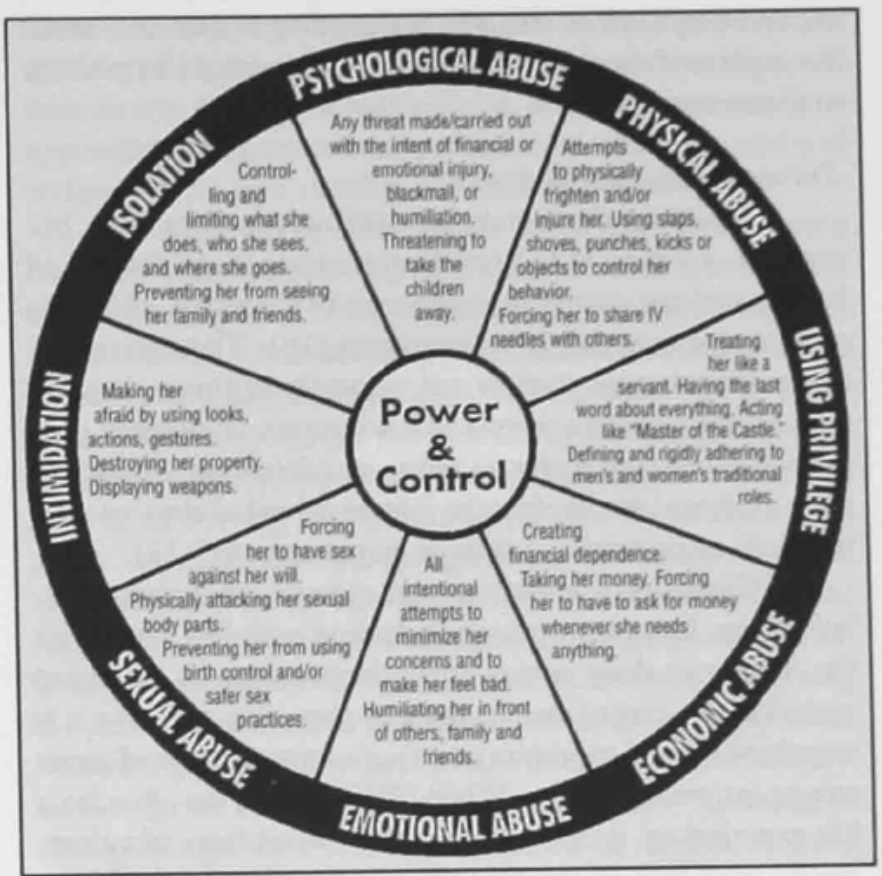

Figure 1: The violence wheel. Reprinted by permission of Peace At Home (formerly Battered Women Fighting Back), Boston.

The current degree of IPV has meant Canadian women in 1996 were six times more likely to be killed by their spouse than by a stranger (12). Although socio-economic factors such as limited education, unemployment and low income $(<\mathrm{Cdn}$ $\$ 15,000)$ double abuse levels compared with the national average, IPV has been widely shown to occur across all racial, ethnic and socio-economic groups (13). Women with disabilities are particularly vulnerable to IPV since $39 \%$ of evermarried Canadian women with a disability or disabling health problem report physical and/or sexual assault. Same sex relationships are not immune from IPV, as $32 \%$ of Nova Scotian lesbians report abuse in a same sex relationship (14). Canadian immigrant women, speaking neither official language, and indigenous women (especially Mi ' $\mathrm{kmaq}$ ) are vulnerable to IPV for cultural and immigration-related reasons. For example, illegal aliens, refugees, or women sponsored by a perpetrator, are likely to remain silent about abuse for fear of deportation. Consequently, $69 \%$ of immigrant women report abuse from husbands. In addition, $70 \%$ of married Native women have been victimized by their husbands (11). Youth and single women are also not free from women abuse. Within dating relationships, young women report an $11 \%$ incidence of sexual abuse, $32 \%$ incidence of emotional abuse, and $18 \%$ incidence of physical abuse (15). 


\section{BARRIERS LIMITING
CLINICIAN RECOGNITION OF IPV}

There are numerous complex factors contributing to failure by clinicians to recognize IPV. Such factors are described hereunder from a collection of past and present studies, and may shift as changes in Canadian health care modifies aspects of the patient-physician relationship and practice environment.

\section{Personal clinician factors}

Health professionals are not immune from IPV. For example, a survey of U.S. medical students found that $5 \%$ of female students currently experience IPV, and $6 \%$ of female students indicate past IPV occurrence (16). Thus, clinicians can be perpetrators, victims and witnesses of abuse. In addition, recent evidence reveals that witnesses of violence (e.g. a child witnessing maternal abuse or adolescent witnessing gang violence) are likely to be later involved in abusive relationships as principle victims or perpetrators (17-18).

Clinicians who have ever been involved in abusive relationships face obstacles while dealing with IPV. As a victim, they may deny or downplay the presence of suspected violence as a coping mechanism, or they may perceive it is somehow normal to endure or inflict a minor degree of abuse among intimate partners. When IPV is among the clinician's life experiences, it often exposes their worst fears of vulnerability or of lack of control (19), and thereby seemingly necessitate repressing clinical suspicions of IPV in later clinical encounters.

Vicarious traumatization of a clinician who has never been an IPV victim is possible when managing IPV. Clinician traumatization is usually in response to hearing stories of another's terror and abuse, and subsequently feeling powerless. This mostly occurs among those exposed to numerous difficult IPV cases, in a setting lacking provider support and counseling, and among those initially ill-trained (20). Retraumatization of providers who themselves have been abused can also occur during clinical encounters. Both forms of traumatization may have adverse outcomes for patients since a clinician's ability to treat IPV patients may be affected, and further interactions with IPV victims may be constrained.

Poor provider coping often occurs when clinicians face IPV alone. The absence of necessary allied health professionals and community advocates can be detrimental to providers, patients, and dependents. Clinicians must realize that they cannot wholly deal with IPV or fully prevent its occurrence. They need to play a role within a multi-disciplinary team (20). Clinicians should engage IPV within a coordinated group including nursing, social work, mental health, clergy, lawyers and law-enforcement officers. Related to professional isolation, a barrier to physician IPV involvement is insufficient key community resources (such as shelters) and inadequate criminal justice system mobilization (20). No less important are barriers posed by poor clinic security measures, sub-optimal law enforcement, and low judicial support of the clinician's role in IPV. Lacking these resources, it is not uncommon for clinicians to avoid IPV cases for fear of personal safety inside and outside the clinic environment.

\section{Barriers between the private and public}

Whether reinforced by a personal experience with abusive relationships or held as an individual viewpoint, clinicians may perceive IPV as a private and not a public health concern (9). This is likened to once-held taboos against clinical inquiry into substance abuse, sexual orientation or sexual practice. In this era, not only is public violence the concern of society, but also violence occurring within the privacy of homes.

Some clinicians judge IPV as a cultural issue, and fear IPV inquiry is tantamount to trespassing. One study cited a clinician who compared IPV inquiry to asking a married woman if she ever has had a lesbian relationship (19). Some also view abuse as a social problem best dealt with between intimates (or intimates and the law), and not between a clinician and one isolated partner. Some view the role of clinical services as only providing care for proximal medical, surgical or psychiatric problems, and not distal psychosocial determinants of illness. Along these lines, Warshaw notes that until recently, medical students were trained to treat IPV physical injuries without investigating the underlying etiology and personal impact of IPV upon the victim (20). There is little doubt that in a busy emergency department (ED), such a clinician might prioritize trauma and other life-threatening illnesses first and fail to recognize the imperative to address the roots of a patient's injuries related to spousal abuse. The clinician may not realize IPV avoidance may result in the patient's re-exposure to continued violence, sometimes leading to her death.

Poor education about the nature of IPV may restrict physicians' ability to screen and diagnose. They may hold restrictive opinions that IPV occurs only when a women is hit by a fist. They may not realize IPV includes a spectrum of abuse and controlling behavior, including threats, neglect, sexual assault and rape, social isolation, verbal abuse and belittlement, denied access to money, goods or transportation, and denial of other necessities $(2,21)$. Clinicians may also fail to recognize IPV if intimate partners are not considered previous partners or partners of the same sex.

\section{Structural constraints}

Related to the ED or primary care environment is the conflict between structural constraints, such as time permitted per patient, and the desire to address IPV. Many perceive the ED or office visit as an insufficient venue to open the "Pandora's box" of issues spilling from IPV detection (19). Some clinicians may doubt their ability to adequately deal with IPV or fear causing more problems. Some clinicians may loathe raising issues and then not being able to fully deal with them due to time constraints, so they choose not to raise the issue at all (20). Related to this, a clinician may not be willing to complete the many tasks of: (a) screening for violence; (b) performing an immediate and long-term safety 
analysis; (c) referring the patient to specialized services; (d) providing community resources; (e) contacting a shelter on her behalf if needed; ( $f$ ) documenting her injuries, taking photographs and conducting a detailed history of the abuse; and (g) providing advocacy for her as she copes with this problem affecting many aspects of her life (and perhaps her dependents).

It has been noted that some clinicians choose to remain silent unless either the patient explicitly requests help to end violence or is in clear and immediate danger. The perceived 'time factor' thus appears able to deter some sincere clinicians from universally screening women who present at a health facility (19). Further, the conceived and real amount of time allowable for IPV cases is related to financial compensation and cost effectiveness. Clinicians may be hesitant to spend long periods counseling and treating women when it diminishes clinic efficiency. In medical systems where physicians receive fee-for-service remuneration (e.g. Canadian Medicare) or where efficiency is closely monitored (e.g. U.S. HMOs), the compensation possible for IPV cases is usually diminished. Thus, in structural terms, clinicians assume that payers may not necessarily value or compensate extensive time spent with one patient.

\section{Barriers related to education}

Medical education lacking IPV training can create barriers when clinicians do intervene. For example, poor documentation of injuries, absence of photographs, lack of direct quotes within the chart, and poor evidence collection (e.g. torn clothing or broken personal articles) can occur among those lacking training. In such circumstances, the clinician is likely to be subpoenaed in order to testify upon her findings. Several such trials, interrupting clinical work, can discourage the well-intentioned clinician from investigating IPV. Physicians may not realize that a complete medical record is often deemed satisfactory by a judge and excuses court appearance (22). Physicians unaware of the role of medical records, law enforcement officers and attorneys, as well as the protocol of the criminal justice system and the legal implications of uncovering IPV, may be ill-prepared to conduct themselves and support their patient. A few sour experiences may discourage the clinician from the vital role of being medical expert, corroborator, and investigator of suspected IPV.

Poorly trained clinicians are more often discouraged by a lack of effectiveness in changing both IPV outcomes and patient willingness to act upon her predicament. Such clinicians often feel powerless to deal with this difficult and recurring problem, and they need education about IPV's pathogenesis, perpetuation and dynamics (19). Despite a clinician's support of the victim, ardent advise to leave the perpetrator, and diligent medical management, many women return to their abusers even after prolonged abuse and medical treatment. Many abused women admit to their clinician that they even still care for the man abusing her. In this setting, clinicians must try to realize that short-sighted prodding 'to just leave' can be misplaced good and not practically possible. Proper education reveals that the woman facing the abuse is the best judge of the safest time to leave, and the clinician should try her best to understand the victim's reasoning even though sometimes this may be difficult and painful.

Professional identity is often at stake in dealing with IPV. In medicine, we are trained to act decisively, and to regard failure, especially during direct patient care, as intolerable. If clinicians view the victim's return to an abusive relationship as failure, the professional's failure aversion may predispose the physician to avoid future interactions with IPV. Clinicians may want to avoid IPV due to feelings of failure and loss of identity (20). Physicians lacking preparation will misconstrue feelings of helplessness, powerlessness, and disappointment as personal and professional weakness, and will endanger their own stability and clinical effectiveness.

A single ED or office visit is not be sufficient to treat a complex violent relationship, and clinicians will become frustrated if trying to 'fix' the abuse solely in conventional biomedical terms. Clinicians may blame themselves and/or blame victims when they feel powerless to stop abuse (19). Clinicians may not recognize the benefits of assessing the situation, providing empowering choices (including reviewing both staying or leaving the relationship), and documenting the abuse. Medical students, if eager to provide hands-on assistance, may not realize the value of simply acknowledging the legitimacy of the woman's situation, expressing concern, offering information and services, and ultimately, conceiving the patient encounter as one small (but necessary) step in the woman's eventual freedom from violence. Unfortunately, knowledge of the expected time course of IPV intervention strategies remains a widespread deficit of medical training (19).

Mandatory reporting laws may make it difficult for the woman to take small but definite steps towards ending abuse. Such sanctions, requiring reporting of suspected violence to authorities, may legally restrict clinicians from engaging the adult victim in informal, yet meaningful dialogue in which she ultimately decides when and how to safely leave the abuse. Clinicians may feel legally required to openly discuss the abuse instead of going slowly and saving some discussions for future visits. The result of such laws may prevent patients from disclosing abuse for fear of police involvement and may discontinue services from a physician who suspects abuse, thus obstructing medical care and a means out of violence (20). Physicians who privately sense their patient's predicament may suspect that formal disclosure by the patient may endanger their patient's safety, and for such reasons, may avoid formally confronting the abusive relationship.

\section{Reforming medical curricula}

In traditional content-oriented training paradigms, clinicians are often trained to provide answers and de facto cures. Problems are often solved from past learning, and clinicians trained this way may be uncomfortable if IPV conflicts with the standard medical treatment model (23). Such clinicians may be less willing to listen, empathize and acknowledge the value of a patient's opinion, and moreso seek objective signs, diagnoses, or treatments. Traditional attitudes may further fail to recognize the social contexts of IPV (20). These contexts 
include psychological entrapment by the abuser, financial and immigration dependency, physical or other disability, concern for children or elders for whom the victim is caring, fear of community or religious ostracization by leaving the perpetrator, racism outside her community, and long-standing isolation and manipulation altering her sense of reality.

A deeper contextual understanding may explain the victim's condition beyond what objective signs may reveal. This view may expose appropriate coping mechanisms in the face of long-standing abuse. For example, rather than diagnosing a passive-compliant behavior, depression, or antisocial personality along strictly psychiatric terms, the physician should realize that these may in fact be appropriate means of protection and diminish chances of further harm. While a woman's substance abuse, suicide attempts, and mental health may be pathological prima facie, they may be her only coping strategies in an increasingly abusive relationship (20).

Traditional education and clinician seniority may limit abilities to deal with IPV. Senior clinicians may have lacked IPV instruction if trained when IPV was considered only a minor medical problem and mainly a social problem $(1,24)$. In response, at Chicago's Cook County Hospital, medical student activists have lobbied to initiate training on IPV for their faculty to reinforce their own knowledge and in response to staff retraining needs (20). Further, even recently trained staff may have only had IPV training 'bundled' among many ethical or social health issues, such that no time existed for students to discuss personal issues critical in coming to terms with this often sensitive issue. They may have lacked small group venues, with clinical and non-clinical preceptors, for students to securely vent gender-based, cultural, or personal issues possibly circumventing later IPV involvement. Further, traditional curricula, which look for medical answers to medical problems, may have failed to acknowledge the value of community involvement in teaching and/or experiential learning (i.e. hearing from violence survivors or spending time at a battered women's shelter).

Despite recent curricular emphasis in Canadian medical schools on IPV training, staff and residents may fail to encourage students to deal with IPV arising during clerkship rotations. When this occurs, skills fade and the link is broken between pre-clinical knowledge and practical skills. Unfortunately, staff physicians or private practitioners may also disapprove of IPV screening by students among their private patients or without their consent (20).

Traditional curricula may lack emphasis on communication skills and empathic, nonjudgmental, and patientcentered interactions. Barriers to being comfortable asking patients about IPV can occur when students are not provided a constructive and encouraging environment to practice asking about violence. This type of training is most suitably done with mock patients, IPV survivors, or experienced clinicians (1). Such skills, highly amenable to being taught, are key to providing a reassuring setting for victims to bring up abuse, where victims are empowered to act in equal partnership with providers, and in which the provider is open to learning from the patient rather than providing all the answers.
It is key to note that IPV is difficult to face in an environment of professional abuse. The traditional medical socialization process must itself be scrutinized to facilitate students' IPV training, and to learn how to question, challenge, and redress abuse in all forms (20). Like some instructors, who may have faced abuse as trainees, some students and housestaff verbal and psychological endure abuse from senior staff, as well as face humiliation, exhausting schedules and fear. Anxiety, isolation and depression are also cited during medical training and can be fueled by the abuse of trainees (20). Such experiences harden students emotionally, physically, and psychologically and uproot the sensibility optimal to providing an empathic environment for an abuse victim seeking a supportive caregiver. Professional abuse and staff unaccountability for abusive practices, can lead to potential re-traumatization when IPV is intersected. Canadian medical schools, such as Dalhousie University (Halifax, NS), have adopted and promoted detailed boundaries of trainee treatment and means of redress (25). Such protocols deserve to be promulgated among all medical schools and clinical institutions.

\section{Barriers to reform}

Practical barriers to recognizing IPV are faced when adding it to curricula or increasing its existing level of teaching. If IPV is a new topic it can lack designated teaching staff and face a general lack of awareness among faculty of its prevalence and management (26). Many medical school curricula already face competition from long-standing departments for limited teaching time (23) and, as a consequence, hesitate to add yet another topic. Unfortunately, family violence remains within the top ten subjects which 1994 medical graduates ranked (out of 41 topics) as receiving inadequate instruction (27).

Even when IPV is added to a curriculum, usually lead by a 'champion' of the cause, the program wanes if the leader leaves or institutional commitment is weak (7). Further, specialized departments and narrowly-focused students may misconceive the applicability of IPV training in their teaching, research and clinical work. Some may feel IPV is an inappropriate use of time. For example, one U.S. clinician stated, "[There is little support within this institution because] hospitals reward practitioners for the wrong things: grants and papers, not patient care. Primary care is not considered a good option to pursue either financially or in terms of status within the medical profession" (7).

This stark view is not wholly unfounded, since Bloom suggests resistance to curricular change is often caused by the traditional role of medical schools to sustain themselves on resources derived from specialized tertiary care and biomedical research $(28,29)$. In such settings, clinicians and students may falsely purport only ED, primary care, or obstetrics and gynecology prospects need be concerned with IPV. Students may mistake the important role of orthopedics, geriatrics, internal medicine, otolaryngology, neurology, and many other specialties in eradicating IPV (30). 


\section{Misconceptions and misinformation}

Even if medical education is appropriate, students and clinicians may possess personal biases affecting their IPV assessment. Some researchers have found clinicians can harbor false suspicions that IPV victims may be partially causative or complicit in their abusive relationship (7). If misjudged as a "deliberate deviant" willfully causing her own condition, staff may respond to abused women as not worthy of intervention (9). Many erroneously believe IPV is restricted to certain ethnic, racial, age or socioeconomic groups (7). Despite contrary evidence, some clinicians cling to a belief that IPV is a problem of the poor, and some believe women of color or ethnic background are more tolerant to abuse compared to Caucasian women (19,7). Students and clinicians may deny IPV occurrence among certain sexual orientations (such as lesbians, gays, or bisexuals), or may hold frank homophobic views preventing them from establishing a meaningful relationship in which disclosure is facilitated.

Some clinicians deny IPV occurs in their demographic community, especially if the community is small and isolated, or if regional competition for patients is high. Reflecting on the protected background of some students, a degree of social naïveté may deter the recognition of IPV among those who have lead sheltered lives (26). Clinicians who have been socio-economically, racially, or culturally secluded may be unaware of the prevalence of abuse and may deny it upon discovery of its extent (20). Such students may be at particular risk to lack personal and professional skills to deal with IPV and other forms of abuse.

\section{Professional barriers}

In a joint practice or hospital setting, clinicians have been discouraged from dealing with IPV by other staff, and those opposing such pressures sometimes face professional marginalization. Treating IPV has often meant psychological, financial and professional harm to clinician's livelihood and careers (7). Clinicians fear the loss of patients if they screen for IPV. In particular, certain families believe the social stigma of being discovered as abusive is too high to allow it to be made even known to their private practitioner. This may be particularly problematic in high-income and prestigious families, and among those in tight-knit social or religious groups regardless of socio-economic status.

Many clinicians have been found to strongly believe that some of their patients will find it offensive to be asked if IPV is occurring. Clinicians also fear offending the alleged perpetrator without 'concrete' evidence (19). Stemming from this clinicians fear a loss of income from patients who may leave the practice if mislabeled. It is also apparent that physicians feel legally vulnerable for drawing conclusions they perceive they cannot legally justify.

Cost barriers within the larger medical system are barriers to both patients and providers. Though American communities face greater barriers to health care based on a high degree of individual economic inequity (7), Canadian health care faces its own challenges to IPV care. In Canada, health care spending has been systematically reduced over many years by government, and only recently, political and public pressure has forced replacement of limited health care resources and social program spending. Lack of facilities, programs, and clinicians are endemic to the Canadian universal health care system. As waiting lists grow for immediately life-threatening conditions (e.g. transplant or cardiovascular surgery) rationalized health care has meant poorer access to programs such as IPV screening. Though many patients and providers contend a high quality of care is still available in most communities, the waiting time and availability of programs has been detrimentally affected. As "clinical-activistscholars" (20), our future roles include continued lobbying for women who have a right to access the highest quality of health care.

\section{CONCLUSION}

A preventative, facilitative and curative approach to intimate partner violence (IPV), or domestic violence, can be adopted by physicians and medical students, among other health professionals. We may be the first point of contact for many women who suffer abuse or who have endured previous abuse (23). It is time we face the moral, medical, costeffective, and regulatory imperatives to aid women, and to quit "underdiagnosing and misdiagnosing" this common problem (31). Curricular, structural, and personal barriers which continue to prevent clinicians from confronting IPV need to be recognized before interventions can be devised. We must further confront the barriers preventing collaboration with community advocates. We must overcome the barriers to devising an intervention plan based on sound strategies such as: prevention, safety, empowerment, advocacy, accountability and social justice.

The effort to understand why clinicians do not investigate IPV to the extent they should uncovers broad medical education issues. It also belies the youth of this movement, dating back only to the 1985 Workshop of Surgeon General C. Everett Koop on Violence and Public Health (31). It raises questions about how physicians should be trained to deal with complex conditions intersecting medicine, society, law enforcement and behavioral change - where no quick fix adhering to either the classical biomedical model or biopsychosocial model is possible. As Warshaw notes, clinicians cannot simply look to IPV victims to diagnose what is wrong, but must look at society, utilizing methods of public health, to uncover the pathogenesis and treatment of this complex social problem $(20,23)$. This paper has listed many barriers to recognizing and dealing with intimate partner violence. However, there remains the more important task of delineating clear strategies to overcome these barriers. With this aim, in the not too distant future, intimate partner violence can be part of medical history, and not part of medical education and practice.

\section{ACKNOWLEDGEMENTS}

This paper is dedicated to the many volunteers helping victims of domestic violence. Thanks to Dr. M. Bell, D.V. Venugopal and R. Venugopal for editorial assistance. 


\section{REFERENCES}

1. Congdon TW. A medical student's perspective on education about domestic violence. Academic Medicine 1997;72:S7-S9.

2. Alpert EJ. Family violence: an overview. Academic Medicine 1997;72:S3-S6.

3. Tjaden P and Thoennes N. Prevalence, incidence, and consequences of violence against women: findings from the National Violence Against Women Survey. U.S. Department of Justice, Office of Justice Programs, National Institute of Justice, Centres for Disease Control and Prevention, NCJ 172837, Washington, DC: Government Printing Office, November, 1998, pg. 8.

4. McLeer SV, Anwar R. A study of battered women presenting in an emergency department. American Joumal of Public Health 1989;79:65-66.

5. Abbott J, Johnson R, Koziol-McLain J, Lowenstein SR. Domestic violence against women: incidence and prevalence in an emergency department population. JAMA 1995;273:1763-1767.

6. Rosenburg ML. Prevention of family violence. Academic Medicine 1995;70:989-992.

7. Cohen S, De Vos E, Newberger E. Barriers to physicians identification and treatment of family violence: lessons from five communities. Academic Medicine 1997;72:S19-S25.

8. Cohen JJ. All in the family: lessons from the dark side. Academic Medicine 1997 http//www.aamc.org/findinfo/aamcpubs/acadmed/ jan1997/janpres.htm

9. Kurz D. Emergency department responses to battered women resistance and medicalization. Social Problems 1987:34:69-81.

10. Krugman RD. From battered children to family violence: what lessons should we learn? Academic Medicine 1995;70:964-967.

11. Nova Scotia Advisory Council on the Status of Women. Violence against women statistical fact sheet. Government of Nova Scotia, Halifax, Nova Scotia.

12. Statistics Canada, Centre for Justice Statistics. Homicide in Canada. Juristat 1996;17.

13. Johnson H. Dangerous Domains: Violence Against Women in Canada. In Statistics Canada. Family Violence in Canada: A Statistical Profile, 1998

14. Smith CG. Proud: but cautious: homophobic abuse and discrimination in Nova Scotia. Nova Scotia Public Interest Group, Halifax, Nova Scotia, 1994

15. Statistics Canada. Violence Against Women Survey, 1993.

16. Ernst AA, Houry D, Nick TG, Weiss SJ. Domestic violence awareness and prevalence in a first-year medical school class. Academic Emergency Medicine 1988;5:64-68.

17. Zuckerman B, Augustyn M, Groves BM, Parker S. Silent victims revisited: the special case of domestic violence. Pediatrics 1995:96:512

18. Statistics Canada. Violence Against Women Survey, 1993. In: Statistics Canada. Family Violence Against Women. A Statistical Profile, 1998.

19. Sugg NK, Inui T. Primary care physicians' response to domestic violence. JAMA 1992;267:3158.

20. Warshaw C. Intimate partner abuse: developing a framework for change in medical education. Academic Medicine 1997;72:S26. S37.

21. deLahunta EA, Tulsky A. Resistance to adding curricula about domestic violence. Academic Medicine 1998;73:726-727.

22. Personal communication. Pualani Enos, JD, Northeastern University School of Law, Boston, MA. Overview of Domestic Violence, Harvard School of Public Health, Boston, MA, Jan. 26, 1999.

23. Rosenburg ML, Fenley MA, Johnson D, Short L. Bridging prevention and practice: public health and family violence Academic Medicine 1997;72:S13-S18.

24. Alpert EJ, Cohen S. Educating the nation's physicians about family violence and abuse. Academic Medicine 1997;72:Svi-Sviii.

25. Dalhousie Medical School, Department of Post-graduate education, Halifax, NS, Canada.

26. Brandt EN. Education and research in adult family violence: a perspective. Academic Medicine 1995;70:968-970
27. Kassebaum DG. Introduction: why another conference on family violence? Academic Medicine 1995;70:962-963.

28. Guze PA. Cultivating curricular reform. Academic Medicine 1995;70:971-973.

29. Bloom SW. Structure and Ideology in Medical Education: An Analysis of Resistance to Change. Journal of Health and Social Behavior 1988;28:294-306.

30. Baker NJ. Strategic footholds for medical education about domestic violence. Academic Medicine 1995;70;982-985.

31. Alpert EJ. Making a place for teaching about family violence in medical school. Academic Medicine 1995:70:974-978

\section{AUTHOR BIOGRAPHY}

Raghu is currently a Master of Public Health student at Harvard University and a Frank Knox Fellow of the Association of Universities and Colleges of Canada and Harvard University. His concentration of study in Boston includes international health and health care policy. He is concurrently a third year medical student at Dalhousie University and received his undergraduate training in physiology from McGill University. He is interested in applying universal screening for violence in clinical settings and preventing violence against women.

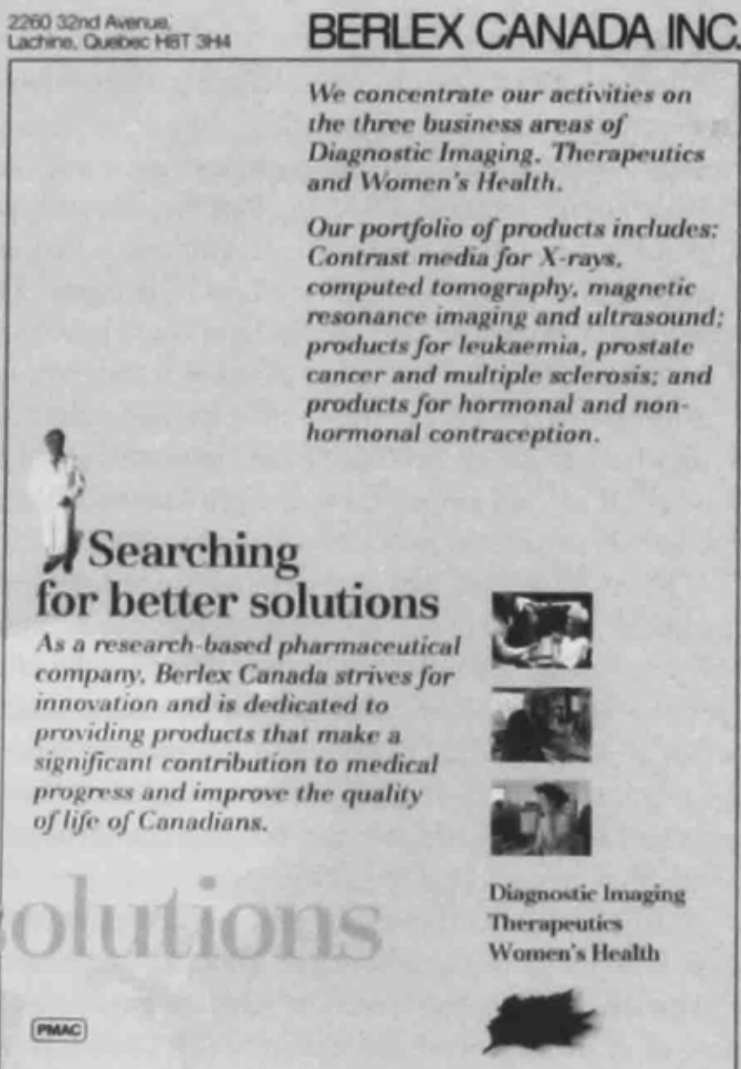

